Images dans le monde ibérique et ibéricoaméricain

9 | 2016

Innovations politiques et culturelles dans les pays andins

\title{
(Re) significaciones de la democracia
}

\author{
En Bolivia en el siglo XXI
}

María Teresa Zegada

\section{(2) OpenEdition}

\section{Journals}

\section{Edición electrónica}

URL: http://journals.openedition.org/agedor/1151

DOI: 10.4000/agedor.1151

ISSN: 2104-3353

\section{Editor}

Laboratoire LISAA

\section{Referencia electrónica}

María Teresa Zegada, " (Re) significaciones de la democracia », L'Âge d’or [En línea], 9 | 2016, Publicado el 01 marzo 2016, consultado el 30 abril 2019. URL : http://journals.openedition.org/agedor/1151 ;

DOI : 10.4000/agedor.1151

Este documento fue generado automáticamente el 30 abril 2019.

L'Âge d'or. Images dans le monde ibérique et ibéricoaméricain 


\title{
(Re) significaciones de la democracia
}

\author{
En Bolivia en el siglo XXI
}

María Teresa Zegada

\section{NOTA DEL AUTOR}

Artículo original, publicado en la Revista Traspatios 2. Revista de la Facultad de Ciencias Sociales. UMSS, Cochabamba, 2011, ha sido actualizado y corregido para la presente publicación.

1 En los últimos años, la democracia ha adquirido centralidad en el debate académico y político, y se ha convertido en un objeto de disputa ideológica. Desde las organizaciones sindicales e indígenas, la discusión en torno a la democracia se ha centrado en la demanda de una mayor participación y ampliación del ejercicio de la democracia representativa hacia otros formatos también legítimos, que se encontraban invisibilizados o recluidos a escenarios particulares de acción política, como la democracia sindical o corporativa que involucra formas de acción y participación democrática directa como las asambleas, la búsqueda de consensos mediante la deliberación, o el mandato imperativo; del mismo modo se han reinstalado en el escenario del debate las formas de democracia comunitaria vigentes desde antes de la colonización española en las comunidades y pueblos indígenas y originarios, basadas en mecanismos de autogobierno, normas y procedimientos propios, y sentidos distintos del ejercicio del poder.

2 Otros sectores políticos y sociales, ante los cambios acontecidos en el campo político y la nueva composición del poder, interpelan a la democracia desde su naturaleza legal e institucional vinculada a la preservación de derechos ciudadanos, el respeto a la ley y la vigencia del Estado de Derecho, como mecanismos de resistencia al actual gobierno y al proceso de cambio emprendido por el Movimiento al Socialismo.

3 En efecto, estas y otras interpelaciones democráticas circulan en el espacio de la discursividad boliviana a través de múltiples y diversas articulaciones, éstas no obstante, 
pueden agruparse fundamentalmente en dos ejes o principios hegemónicos articuladores: uno asociado al esquema liberal representativo y de derechos individuales que remite a la defensa del Estado de derecho, a la legalidad y a la estabilidad del sistema representativo; y otro que deviene más bien de su crisis, parte del reconocimiento e incorporación de formas alternativas o complementarias de ejercicio político ancladas en la sociedad y las organizaciones, y del reconocimiento de los derechos colectivos y la profundización de la participación social en el Estado.

4 Así, en el debate político y simbólico, la noción de democracia se encuentra vacía de contenido y adquiere sentido en la medida en que se articula a algún principio articulador o hegemónico particular ${ }^{3}$. En otras palabras, la discusión sobre la democracia o los adjetivos que se le atribuyan, se sitúan en el terreno de la disputa política estructural entre principios hegemónicos distintos que pugnan por el poder y por (re)articular los elementos ideológicos - en este caso la democracia -, que resultan fundamentales en determinada coyuntura, a sus respectivos discursos otorgándole sentido.

Particularmente en situaciones de crisis hegemónica y política, se producen procesos de desarticulación/rearticulación discursiva, ya que durante periodos de estabilidad del sistema político y reproducción de los formatos habituales de la representación, las clases dominantes logran absorber las posibles contradicciones y las neutralizan mediante la instalación de un régimen de verdad ${ }^{4}$ asumido e internalizado por la sociedad. En cambio, en situaciones de crisis, al perder su capacidad de interpelación, se produce un proceso de disolución discursiva y se genera la circulación y posibilidades de (re)articulación de aquellos elementos ideológicos que adquieren centralidad en el campo político.

6 En Bolivia, la democracia representativa junto a los otros elementos constitutivos del modelo anterior, como el neoliberalismo, la democracia pactada, el monopolio partidario, y otros, fueron cuestionados por la sociedad y las organizaciones, no solo mediante el cambio de la preferencia electoral en las elecciones nacionales del 2002, y con más contundencia del 2005, 2009 y 2014; sino también mediante la construcción de una demanda colectiva de una profunda reforma estatal que abarcaba, entre otras cosas, la profundización de la democracia, el reconocimiento de las identidades étnico-culturales, el cambio social, e inclusive la invocación al socialismo, que se plasmaron en un proceso constituyente iniciado a mediados del 2006 y que culminó el 2009 con la aprobación de un nuevo texto constitucional. Dicho proceso fue sostenido por la vigilancia y una serie de movilizaciones sociales desde inicios de la actual década.

\section{Lecturas sobre la crisis de la democracia}

7 Los problemas emergentes tanto de las concepciones restringidas de la democracia y de su ejercicio político limitado al plano electoral, como de las distorsiones por el predominio de intereses particulares, han sido abordados de manera extensiva por la ciencia política en las últimas décadas. Varios autores, han llamado la atención sobre las debilidades en el funcionamiento de la gestión pública y política de la democracia, así como sobre los déficits de la representación. Autores que provienen de la ciencia política clásica como Norberto Bobbio ${ }^{5}$, llamaron la atención sobre el conjunto de falsas promesas o promesas incumplidas de la democracia, argumentando que de una democracia del individuo y pueblo soberanos se habría pasado a una democracia de los grupos poderosos que se convertían en los protagonistas de la vida política provocando un efecto centrífugo, la fragmentación de intereses y el predominio del neo corporativismo, 
caracterizado por la presencia de grupos de interés particulares en la política, por encima de la preservación del bien público, distorsionando de esa manera los principios y fines de la democracia; también se refería a los poderes invisibles de la democracia como aquellos que, desde los intersticios del sistema, rigen la práctica política y reorientan de manera subrepticia sus objetivos.

Otras tendencias críticas han puesto atención en otros aspectos, como por ejemplo, los déficits de gestión pública del régimen político democrático, identificando como uno de sus orígenes el presidencialismo en América Latina. Es el caso de Linz - Valenzuela y otros $^{6}$, que argumentaban a favor del parlamentarismo como el régimen más adecuado para el desenvolvimiento de la democracia. Otros estudios se enfocaban de manera más precisa en el desempeño político de las instituciones, la corrupción, la gobernabilidad y por supuesto la representación; tema que estuvo y está en la preocupación de autores como O' Donnell, Novaro o Portantiero ${ }^{7}$, y muchos otros que reflexionan en dicho sentido.

De ahí que, centrados sobre todo en la noción de democracia como desarrollo institucional y gobernabilidad política, los gobiernos de América Latina en las últimas décadas, han propiciado una serie de reformas institucionales, muy importantes por cierto, pero que encaraban solo parcialmente los problemas del sistema democrático. Se han buscado soluciones centradas en la gestión estatal de la democracia, tendientes a eliminar administraciones patrimonialistas y clientelistas, o la corrupción; en ese sentido han promovido la incorporación de mecanismos de rendición de cuentas o control democrático y transparencia en la gestión. Otro conjunto de reformas se ha concentrado en la búsqueda de soluciones por la vía gerencial, es decir, buscando mejorar la eficiencia de la administración pública mediante el traslado de criterios del sector empresarial privado al ámbito público.

Sin duda estas iniciativas han logrado resultados positivos, pero resultan al mismo tiempo limitadas, pues no lograron encarar los aspectos estructurales críticos de la democracia y la gestión pública y política. Si en cambio, partimos de un concepto ampliado de gobernabilidad, entendida como la capacidad del Estado de satisfacer las necesidades y demandas sociales sobre las cuales sostiene su legitimidad, - trascendiendo la noción habitual restringida a la capacidad de generar pactos políticos entre los actores del sistema $^{8}$ - concluimos que uno de los problemas centrales de la democracia reside precisamente en la relación del Estado con las condiciones de la sociedad sobre la cual se sostiene; es decir, con las contradicciones y conflictos económicos, sociales y culturales.

De esta manera, si no se incorporan estos factores de análisis como parte sustancial de la crisis, difícilmente se pueden establecer soluciones de largo plazo. La persistencia de situaciones críticas en varios países de América Latina así como el cambio en la orientación de los gobiernos como el denominado "giro a la izquierda latinoamericano" que habría promovido un escenario post liberal caracterizado por la hibridación política", dan cuenta de estos déficit y de la necesidad de buscar soluciones innovadoras.

12 Estos acontecimientos han demostrado las limitaciones de los parámetros habituales de interpretación de la realidad y sus efectos en el campo político, por lo que se ha establecido la necesidad de una lectura crítica y renovada de la relación entre el Estado, el sistema de representación política y sociedad.

13 En Bolivia, de manera concurrente con las reflexiones latinoamericanas, durante la década de los ochenta y noventa, se ensayaron diversas interpretaciones de la realidad democrática ligadas a la necesidad de modernización del Estado, a mejorar la 
transparencia y eficiencia del régimen democrático y a la gestión de los partidos políticos en el Estado, dentro del horizonte de estabilidad del orden político como factores complementarios al régimen económico neo-liberal. Mientras otras lecturas hacían énfasis en la necesidad de generación de acuerdos y consensos para fortalecer la gobernabilidad democrática adecuada al cambio moderno, así como a los procesos de ampliación de la participación social y la representación son analizadas desde una perspectiva "neo populista", como en Archondo, y otros ${ }^{10}$. Por último, surgieron otras miradas ligadas a la participación popular y la reciente territorialización de la política, entre muchos otros.

Otro conjunto de autores partieron de una matriz de pensamiento distinta que daba cuenta de la persistencia de estructuras coloniales en la configuración política y pública, atribuyendo a estas prácticas recurrentes los déficit de la democracia representativa y los principales problemas de representación del sistema política en Bolivia, en otras palabras, los problemas de representación tenían su raíz en la aplicación irreflexiva y mecánica del esquema liberal sobre una realidad diversa, abigarrada ${ }^{11}$, una realidad "multisocietal" y "multicivilizatoria"12 caracterizada justamente por la diversidad estructural y étnicocultural ${ }^{13}$.

nera concurrente con estas reflexiones intelectuales, se produce la construcción colectiva de un discurso de reivindicación socio cultural, que se inicia a principios de los noventa con la "Marcha por el Territorio, la Dignidad y la Vida" protagonizado por los pueblos indígenas del oriente, cuestionando el Estado monocultural y neoliberal, que tiene correlato en convenios internacionales como el 169 de la OIT. Más adelante, estas mismas organizaciones generan la necesidad de una profunda transformación estatal mediante la exigencia de una Asamblea Constituyente, promoviendo el debate al interior de sus organizaciones y consensuando uno de los ejes centrales de la propuesta que tuvo mayor influencia en la nueva Constitución, como es el Estado Plurinacional.

Esta rápido recorrido histórico al caso boliviano, pone en entredicho la concepción del Estado y el sistema político como espacios exclusivos de lo político, y sitúa a la sociedad civil y sus organizaciones como espacios privilegiados donde, desde fuera de las fronteras de lo institucional/formal/representativo, se organiza y discurre el poder.

En consecuencia, la democracia no puede leerse solo en sus anclajes institucionales sino fundamentalmente en su relación con la sociedad civil, las organizaciones sociales y las contradicciones estructurales que de ella emergen.

\section{Déficit histórico de representación democrática}

En América del Sur, la incorporación de la democracia representativa, - o "popular" como se había denominado en la primera constitución boliviana-, no fue precisamente producto del proceso de industrialización y modernización como en los países del occidente europeo, sino que fue introducida tempranamente como parte del ordenamiento jurídico y político que siguió a los procesos de independencia. En muchos casos, completamente desligado de la realidad política y socio-cultural en que se debatían las mayorías nacionales, por tanto, no cumplió la función homogenizadora de las sociedades avanzadas.

Particularmente en el caso boliviano, se asentó sobre una sociedad abigarrada y compleja, en la que no se cumplía el principio de la democracia representativa como cuantificación 
de la voluntad colectiva, porque para comenzar, el porcentaje de población habilitada como ciudadana para ejercer sus derechos políticos era mínima, pero sobre todo porque no existían las condiciones materiales para la liberalización del individuo, que recién se cumplieron en la revolución del 52, y por las limitaciones de un sistema políticamente homogenizante sobre una sociedad esencialmente plural que presentaba fracturas políticas relacionadas con las luchas sociales, en cuyos núcleos se definía la política.

Decíamos que la Revolución de 1952 sentó las bases de democratización social porque consolidó la reforma agraria, la construcción del mercado, y por tanto, permitió la liberalización del individuo, libre de la tutela hacendal, así como por la conquista del voto universal. Sin embargo, este proceso resultó limitado por varias razones, entre otras, porque no logró encarar el problema de la diversidad estructural del país, sino que se basó en la supuesta homogenización social bajo las categorías de campesinado o pueblo que, como veremos más adelante, encubrieron una realidad social diferenciada y diversa.

21 Más adelante, la política discurriría en la confrontación entre las fuerzas armadas y la Central Obrera Boliviana, desprovista de mediaciones políticas. Con las movilizaciones por la recuperación de la democracia a fines de la década de los setenta, se incorporó la democracia representativa al acervo político o a las acumulaciones hegemónicas de la masa, como destacaba Zavaleta Mercado ${ }^{14}$. En ese momento, el autor se preguntaba cual era el rol efectivo de la democracia representativa en un país en que la política se definía por la presencia de sectores estratégicos que ocupaban de manera predominante el campo político, o zonas geográficas determinadas.

Esta reflexión remite nuevamente a la eficacia de la democracia representativa - un hombre un voto - como expresión de la voluntad política colectiva, pues de acuerdo a su hipótesis los procesos políticos se dirimían mediante la presencia de una mayoría efectiva o mayoría de efecto estatal ${ }^{15}$. Así, quien electoralmente se imponía en las ciudades principales del país y controlaba los distritos mineros o centros campesinos más importantes, y además tenía apoyo de parte del ejército, definía los resultados de la política. En el fondo, se refería a la existencia de núcleos decisivos donde se dirimía la política más allá de la mera cuantificación del voto.

Por último, con la recuperación de la democracia se inicia un nuevo ciclo histórico protagonizado por los partidos políticos como sujetos exclusivos de la representación política, a quienes la democracia les exige el cumplimiento de determinadas funciones mediante las cuales el sistema político se relaciona con la sociedad. Teóricamente, las exigencias funcionales de la democracia ${ }^{16}$ a los partidos políticos son las siguientes: selección de élites y conformación de gobiernos, la gestión pública, la representación, la mediación agregación y articulación de intereses, la canalización de demandas, entre las principales; pero en Bolivia, dichas funciones se han limitado solo a la competencia electoral, la conformación de gobiernos y la administración y gestión de los mismos. Las otras funciones, sobre todo aquellas relacionadas con la sociedad han sido abandonadas por los partidos políticos y asumidas espontáneamente por otros actores de la sociedad civil como los medios de comunicación, la iglesia, las ONG's, u organizaciones sociales, ampliando aún más la brecha entre el sistema de representación política y la sociedad civil por lo que, al menos en el caso boliviano, no se puede hablar strictu sensu de la existencia plena de un sistema de representación política, cuando éste no ha logrado asumir sus funciones esenciales ${ }^{17}$. entre el sistema político formalmente edificado sobre la Constitución Política del Estado y 
la dinámica de la sociedad, sus organizaciones, demandas y expectativas, que solo eventualmente y por presión social, han logrado ser atendidos por el Estado.

Por último, en relación con la gestión estatal de la democracia, los principales déficits de la conducción partidaria compartidos con las otras democracias representativas de la región, han girado en torno a una débil institucionalidad acompañada por una cultura política caudillista, clientelista y patrimonialista. En el caso de Bolivia, el patrón de interacción partidaria denominado democracia pactada ha provocado distorsiones en la administración y gestión pública; por otra parte, mientras el Estado promovía un proceso de modernización económica, como afirma Calderón ${ }^{18}$, la gestión pública, continuaba sostenida sobre el patrimonialismo corporativo del pasado.

De esta manera, a raíz del divorcio entre el sistema de partidos y la sociedad, las organizaciones sociales optaron por recurrir a formas de auto representación social en el campo político para buscar la atención a sus demandas a través de medidas de presión abierta contra el Estado, desestimando los canales de mediación institucional establecidos por el sistema de partidos, lo cual le restó aún más legitimidad al sistema de representación.

Esta reorientación se verificó en dos planos: en el plano electoral mediante la participación de candidaturas en elecciones municipales y nacionales alternativas a las partidarias, a través de Agrupaciones Ciudadanas que fueron copando progresivamente espacios de poder ${ }^{19}$; y en el plano de la acción colectiva directa mediante movilizaciones sociales, las que lograron cambios tanto de políticas públicas a favor de los trabajadores, como la incidencia en decisiones políticas de alto nivel como sucedió con la expulsión de Gonzalo Sánchez de Lozada en octubre del 2003 y luego, la renuncia de su sucesor Carlos Mesa a mediados del 2005.

Estas organizaciones políticas de raíz sindical que incursionaron en el campo político, se encuentran muy distantes de aquellas formas de organización tradicional de los partidos políticos ${ }^{20}$, aunque no están exentas de reproducir la cultura política y comportamientos por ellos cuestionados.

En definitiva, si bien durante los noventa se ha aplicado un proceso sostenido de reformas para construir ciertos grados de institucionalidad democrática, no se han logrado encarar sus principales debilidades y tampoco se han podido resolver en el campo político, las distancias estructurales entre la sociedad y el Estado, visibilizadas a principios del siglo XXI, cuando emergen nuevos referentes de acción política y auto representación desde la sociedad y sus organizaciones cuestionando estructuralmente este modelo y promoviendo su reversión. Dados los diversos componentes de la dinámica política actual, es preciso partir de una noción ampliada o en su caso, alternativa, de democracia que no se restrinja a los cánones de la práctica representativa o a su faceta eminentemente electoral, sino que abarque a la sociedad, sus formatos organizativos y de autogobierno, particularmente vigentes en las organizaciones sociales y en los pueblos indígenas y originarios.

\section{Nuevos referentes y lecturas en torno a la política y la democracia}

Los factores críticos de las democracias latinoamericanas $y$, en particular el cuestionamiento al orden político suscitado en Bolivia desde inicios del siglo XXI, conducen a buscar nuevas lecturas e interpretaciones sobre la democracia. En ese sentido, 
como sostiene Raventós, el proyecto democrático-participativo del siglo XXI se orienta a la ampliación del campo de la política y la construcción de ciudadanía por medio de innovaciones en la relación entre Estado y sociedad, así como de la (re)politización de los conflictos y su (re)significación en el campo político, al mismo tiempo que se revelan las limitaciones que residen en su naturaleza limitada y fragmentaria ${ }^{21}$.

31 Para ello, es preciso abandonar una visión unilateral de la democracia asociada a la estabilidad institucional y a la gobernabilidad, y en cambio partir de las contradicciones socio económicas en que el objetivo de la política, más que atacar los conflictos y mitigarlos, consistiría en movilizarlos, ponerlos en el centro del escenario, visibilizarlos en el marco de la expresión del pluralismo. Así, siguiendo a Mouffe (1999) ${ }^{22}$, las contradicciones que se generan en la sociedad, lejos de representar un peligro para la democracia son su condición de existencia. En esa misma línea reflexiona Tapia sobre la necesidad de partir un concepto de democracia como 'condición lejos del equilibrio'.

Por otra parte, el concepto acuñado por Laclau (2009) ${ }^{23}$ de democracia radical, apunta en la misma dirección, en que se destaca el desarrollo horizontal de las relaciones entre organizaciones y movimientos sociales que en su interacción empiezan a generar efectos políticos; desde su perspectiva, la democracia se radicaliza en la medida en que sectores que no participaban en las definiciones públicas comienzan a lograr una expansión continua en el ámbito de decisiones estatales.

33 En efecto, la democracia denota una manera de ser de lo político ${ }^{24}$, o un modo de subjetivación de lo político que no puede leerse al margen de la sociedad sobre la cual se sostiene, es decir, las contradicciones y conflictos económicos, sociales, y la cultura política que se constituyen en la base, y al mismo tiempo en los límites de su desempeño ${ }^{25}$. La preocupación entonces deviene de la necesidad de atender las características de las sociedades democráticas $\mathrm{y}$, paralelamente, buscar maneras de convivencia social y política, - de gobernabilidad - que se verifiquen en el campo político, al respecto Mouffe plantea el concepto de pluralismo agonístico democrático, que construye la democracia liberal para proteger las instituciones democráticas, abandonando la perspectiva racionalista que lleva al antagonismo, y tendiendo más bien a desactivar el antagonismo potencial que existe en las relaciones sociales y en el proceso de construcción de identidades colectivas, y transformarlo en agonismo, como una manera de "convertir al enemigo a abatir, en un adversario al que se debe tolerar" ${ }^{26}$.

De esta manera se produce una ruptura con las formas tradicionales de lectura de la democracia y se desplazan las preocupaciones del campo estrictamente político institucional al sociológico y cultural, partes consustanciales a las definiciones de lo político y del poder.

De ahí que, acudimos al concepto de 'campo político' propuesto por Pierre Bourdieu ${ }^{27}$ porque esta categoría permite abarcar una dimensión más amplia de la acción, instituciones, sistemas y discursos políticos con que operan los sujetos sociales. El campo político, visto como un campo de fuerzas, revela los principales espacios de conflicto y los actores que se constituyen en torno a la disputa por los capitales o recursos en juego; en definitiva, pone en evidencia la lucha por el poder.

En el mismo sentido, Dussel ${ }^{28}$ a partir de un análisis teórico minucioso de los "momentos" de lo político, sus dimensiones y esferas, propone un acercamiento a lo concreto, conflictivo y crítico de la realidad política y sus posibilidades de deconstrucción y paralela construcción de un orden político alternativo. El autor asume el concepto de campo 
político, cercano al de Pierre Bourdieu, para delimitar el objeto de la y lo político y diferenciarlo de los otros campos del mundo cotidiano. De ahí que "el campo es el espacio de interacciones, cooperación, coincidencias y conflictos, que remite a la esfera de las luchas hegemónicas por el poder". El autor puntualiza que "Todo campo político es un ámbito atravesado por fuerzas, por objetos singulares con voluntad, y con cierto poder. Esas voluntades se estructuran en universos específicos (...) cada sujeto, como actor es agente que se define en relación a los otros". El concepto de campo político, desplaza o más bien amplía el análisis hacia la sociedad civil y permite identificar la red de relaciones de fuerzas o nodos, en que cada ciudadano, cada representante o cada organización opera.

Del mismo modo, resulta pertinente ampliar la noción de poder, que no se restringe a los espacios convencionales de gestión y acción política sino que abarca todos los intersticios de la vida social. Como sostiene Foucault ${ }^{29}$, el poder no se localiza en una institución o en el Estado, no se posee, sino que se ejerce, y se encuentra diseminado en las distintas dimensiones de la vida social y política, en sus hogares moleculares. En otro texto señal que "en todo lugar donde hay poder, el poder se ejerce. Nadie es dueño o poseedor, sin embargo sabemos que se ejerce en determinada dirección; no sabemos quién lo tiene pero sí sabemos quién no lo tiene".

Lo cierto es que la política y la lucha por el poder involucran una disputa sobre el conjunto de significaciones culturales, y el cuestionamiento a las prácticas dominantes relacionadas tanto con los universos simbólicos como con la redistribución de los recursos. En efecto, remite a la constitución de una nueva gramática social capaz de cambiar las relaciones de género, de raza, de etnia y la apropiación privada de los recursos públicos, e implica una nueva forma de relación entre el Estado y la sociedad ${ }^{30}$.

Ahora bien, la diferenciación conceptual que introdujo Gramsci (1978) ${ }^{31}$ entre dominación - fase que denota una crisis, pérdida de consenso y la necesidad de acudir a la coerción y dominación violenta - y hegemonía - como consenso de una mayoría determinante -, permite distinguir distintos órdenes políticos y sus capacidades hegemónicas. El autor utiliza el concepto de creación de consensos para referirse a los acuerdos asumidos por sujetos libres, autónomos, racionales y con capacidad de intervención discursiva para unir voluntades y lograr un objetivo de poder determinado. De ahí que, los sujetos alternativos se conformen en el campo político como movimientos sociales contestatarios, anclados en la exclusión, la opresión y la marginación, y con la responsabilidad de deconstruir el orden vigente y generar uno nuevo. En principio son portadores de reivindicaciones particulares y diferenciadas para luego interpelar a actores colectivos afines que pueden convertirse en una situación estratégica, o en su caso en un momento constitutivo ${ }^{32}$.

41 En su carácter potencial, el poder reside en el pueblo (potentia) que, de acuerdo a Dussell, es una red de interacciones y nodos - recurriendo a un concepto de Manuel Castells -, capaz de generar un proceso de toma de conciencia del poder en si, y de constituir organizaciones para acceder al control del poder político institucional (potestas), es decir orientarse hacia la objetivación del poder. De acuerdo al autor, el poder se tiene o no se tiene, en ningún caso se toma. Para una aproximación más cercana al funcionamiento del orden político vigente, recurre al concepto de sistema, a partir del cual propone caracterizar a los sistemas como liberales, socialistas o de participación creciente, categoría empleada por el mismo autor para caracterizar al régimen del actual presidente boliviano Evo Morales. 

permite ejercicios delegados del poder legítimo, e inclusive alienta la existencia de minorías y del disenso. Introduce el concepto de democracia crítica social para caracterizar el nuevo régimen que asentado sobre el cuestionamiento a las estructuras hegemónicas del sistema y establece la necesidad de contar con estructuras organizativas democráticas, conformadas de abajo hacia arriba, criticando severamente a las organizaciones partidarias que se habrían convertido en meras maquinarias electorales.

Otro autor que marca un derrotero en las nuevas lecturas de la democracia es Santos ${ }^{33}$ con el concepto de demodiversidad. Este concepto parte de la coexistencia de distintos formatos de democracia en un contexto histórico determinado. La noción de demodiversidad busca compatibilizar la eficiencia político-institucional con la equidad social, se sostiene en el reconocimiento de que además de la democracia representativa liberal, existen otras formas de democracia como la iniciativa popular, participativa, o comunitaria. Sin embargo, el aspecto novedoso de esta noción es posicionar las distintas formas de democracia sin subordinarse a la liberal representativa, mediante criterios transculturales, la democratización de los saberes, la autoridad compartida, y los movimientos y organizaciones sociales como protagonistas; en definitiva, se trata de democratizar la democracia.

En términos metodológicos existe la necesidad de desplazarse del ámbito políticoinstitucional al espacio de relaciones, articulaciones y tránsitos entre Estado sociedad civi $^{34}$ donde se dirime la disputa entre los proyectos hegemónicos cambiando el enfoque de la democracia tradicionalmente situada en el análisis del sistema político institucional.

Un factor que va cobrando cada vez más relevancia en el proceso de transformaciones, es su materialización institucional, es decir, la necesidad de que los nuevos formatos de democracia adquieran un carácter concreto. Un proceso de (re)institucionalización de la política, que incorpore el conjunto de innovaciones institucionales, formas de participación social en espacios de decisión y control, mecanismos y espacios públicos que aseguren que los diferentes intereses y posiciones estén presentes en el debate y deliberación nacional y local, y la automática redistribución del poder.

La democracia también va mutando su contenido y produce nuevos efectos de verdad, que (re)definen lo que es y no es aceptable; pues las condiciones del discurso y los propios discursos no son dados de una vez y para siempre, sino que se transforman a través del tiempo, mediante cambios generales y relativamente repentinos de un episteme a otra ${ }^{35}$. En ese sentido, en Bolivia se ha producido un desmontaje de la eficacia simbólica de la democracia representativa instaurada como régimen de verdad en el periodo neoliberal mediante un desanclaje de las estructuras institucionales objetivadas y la generación de nuevas articulaciones democráticas en los discursos y propuestas de sujetos alternativos que en este momento hegemonizaban el campo político.

Por último, no es posible repensar la democracia sin plantear la dimensión de ciudadanía.

El ejercicio de la ciudadanía se encuentra estrechamente vinculado con el régimen político democrático, que precisamente se convierte en el garante de los derechos ciudadanos. La noción de ciudadanía retorna al centro del debate, debido a las contradicciones no resueltas que provienen de los problemas de desigualdad social, discriminación y exclusión. De esta manera, la inacabada construcción del Estado-nación y su correlato en una ciudadanía universal, es interpelada por una realidad en la cual 
conviven tiempos heterogéneos ${ }^{36}$, que demandan formas de pertenencia, reconocimiento y respeto a la diversidad.

48 Así, desde las perspectivas discursivas indígena-originarias, la ciudadanía se articula al reconocimiento de los derechos colectivos y las identidades originarias; desde otras concepciones más radicales se contrapone a la autodeterminación o libre determinación de los pueblos. Esta visión ampliada de ciudadanía ha sido recogido en el nuevo texto constitucional y fue iniciativa de las nueve organizaciones indígenas más importantes de Bolivia de oriente y occidente, cuyo epítome es el Estado plurinacional ${ }^{37}$.

\section{Pensar la democracia desde la nueva Constitución boliviana}

Las reformas estatales introducidas en la nueva CPE marcan transformaciones en diversos sentidos, la ampliación de derechos individuales y colectivos, la modernización del Estado, la ampliación de la participación social en la gestión pública, la incorporación de nuevos paradigmas ${ }^{38}$, así como nuevos formatos de democracia que conviven con la democracia representativa y directa que se encontraban establecidas en la anterior Constitución.

En efecto, se establece una compleja y no resuelta convivencia entre la matriz republicana liberal plasmada en el Estado de Derecho, y la indígena originario campesina anclada en el Estado Plurinacional Comunitario e intercultural. Se trata de una co-habitación compleja, pues la primera se basa en principios universales e igualitarios extendidos a todos los ciudadanos bolivianos, mientras la segunda se basa en prácticas particulares y específicas del ejercicio político comunitario basada en usos y costumbres. La complejidad de esta coexistencia enunciada en el texto constitucional, se verifica en el momento de su aplicación.

51 Así, se establece como sistema de gobierno las formas "directa y participativa, representativa y comunitaria". La directa y participativa por medio del referendo, la iniciativa legislativa ciudadana -que ya estaban contempladas en la anterior constitución-, la revocatoria de mandato, la asamblea, el cabildo y la consulta previa que son una innovación que conduce a la ampliación de los mecanismos de ejercicio directo, aunque las asambleas y los cabildos tienen solo carácter deliberativo (Art. 11 inc. 1). Pero la verdadera innovación, es la inclusión de la democracia comunitaria que se ejerce "por medio de la elección, designación o nominación de autoridades y representantes por normas y procedimientos propios de las naciones y pueblos indígena originario campesinos, entre otros, conforme a Ley" (Art. 11 inc. 3). La mención general "normas y procedimientos propios' responde a la diversidad de formas de ejercicio del poder y de autogobierno en las comunidades que conviven con formatos liberal representativos. El desafío se encuentra, justamente, en encontrar la ingeniería jurídica adecuada para su articulación.

Este nuevo formato de democracia - demodiversa - se materializa en la denomiada autonomía indígena, que consiste en "el autogobierno como ejercicio de la libre determinación de las naciones y pueblos indígenas originario campesinos cuya población comparte territorio, cultura, historia, lenguas y organización o instituciones jurídicas, políticas sociales y económicas" (CPE); probablemente es el espacio en que mejor se pueda anclar el ejercicio de la democracia comunitaria reconocida constitucionalmente. 
53 En todo caso, para la construcción de la nueva trama institucional de la política es preciso generar formas articuladas entre los diversos modos de gobierno y organizaciones socio políticas existentes. Mediante por ejemplo, la noción del "núcleo común", o núcleo intercultural democrático, que se expresa evidentemente en la igualdad jurídica, pero sostenido sobre la igualdad en la esfera productiva.

Para imaginar estas articulaciones, se debe comenzar por romper - como hemos insistido a lo largo del texto - con la visión procedimental de democracia, y partir de "las sociedades en su historia", así como de una nueva gramática de organización de la sociedad y de las múltiples relaciones con el Estado.

El tema se complejiza cuando, en la realidad se constata la difícil convivencia entre la democracia comunitaria y la democracia liberal. Silvia Rivera plantea que la tensión proviene de un paradójico empate de racionalidades "por el cual, ni las formas de democracia de ayllu han sido abatidas totalmente para dar curso a los comportamientos políticos liberales e individualistas basados en la imagen del "ciudadano", ni los comunarios disfrutan, por lo tanto, de un status diferente al de colonizados y marginalizados - por ser indios - de los beneficios de la sociedad democrática" ${ }^{39}$, en una suerte de tensión irresuelta que cobra fuerza, se visibiliza y se expresa en el nuevo texto constitucional.

Las formas democráticas comunitarias han sido abordadas por distintos investigadores conceptualizadas como democracia comunal en unos casos, o democracia étnica, en otros o por último como democracia de ayllu. Si bien cada comunidad contiene características particulares, comparte varios rasgos comunes, entre ellos el carácter colectivo de la toma de decisiones y de administración del poder, presente en el mundo andino, concretamente en el Norte de Potosí, donde persisten estructuras organizativas tradicionales con distintos niveles; mientras en otras regiones como La Paz, las formas de organización política tradicional se han conjuncionado con el modelo sindical. Otros elementos comunes son los cabildos, la rotación de cargos, la obligatoriedad en el cumplimiento de funciones de autoridad; la participación de la comunidad en la toma de decisiones, el consenso deliberativo a través de la asamblea como máxima autoridad de mando (mandato) colectivo, la concepción de la autoridad como servicio y no como privilegio, sistemas de rendición de cuentas y control social, la revocatoria de mandato entre otros.

57 También es preciso mencionar, las formas de organización política que rigen en los sindicatos, y que se han ido construyendo a partir de las primeras décadas del siglo XX y en particular después de la revolución del 52, que prevalecen potentemente en los sectores laborales, vecinales, gremiales y campesinos. En ellas se practica el asambleísmo, el mandato imperativo, las decisiones por consenso o en su caso por unanimidad, ahora reconocidas como instancias de deliberación por la nueva Constitución.

Con todo, el desafío es establecer las articulaciones adecuadas entre los distintos formatos de ejercicio democrático, para hacer efectiva la participación en la toma de decisiones públicas en los ámbitos correspondientes.

\section{¿Cómo democratizar la democracia?}

La democracia es un proceso en construcción, es decir, no termina de asumir su forma y contenido plenos, sino que se va redefiniendo y resignificando en el tiempo en estrecha 
relación con los procesos históricos, las hegemonías políticas y los regímenes de verdad. Los momentos de crisis permiten dar saltos cualitativos y replantear las formas democráticas adaptándolas a la dinámica política. Uno de los factores de la crisis, largamente señalado por Zavaleta, fue la no correspondencia de la sociedad civil con el Estado político a lo largo de la historia de Bolivia ${ }^{40}$.

Por otra parte, no es concebible este proceso al margen de las organizaciones sociales y la participación activa de la sociedad, como una forma de presión "de abajo hacia arriba", desde el mundo de lo profano. Si partimos de la idea central de que la democracia es la posibilidad política de las sociedades de participar en las decisiones relacionadas con asuntos públicos, su profundización debe partir de las características y necesidades de las propias sociedades y de la presencia comprometida de sus actores.

61 Esto nos lleva a comprender y asumir las causas que dieron lugar a la crisis del sistema democrático y los mecanismos tradicionales de representación política, que condujeron a la desconfianza y descrédito ciudadano y a su cuestionamiento. Si bien esta crisis tiene sus raíces en las instituciones democráticas y sus actores (los partidos), también responde a la impronta de la sociedad y sus organizaciones y prácticas políticas.

De esa manera, el cuestionamiento y crisis del sistema político en Bolivia, permitieron las transformaciones institucionales consecuentes que han sido plasmadas en el nuevo texto constitucional: la representación de la diversidad social y cultural en el ámbito político, las formas de ejercicio del poder alternativas o complementarias a la democracia liberal y su reconocimiento junto a la democracia representativa; la autonomía indígena con un nivel jerárquico similar a los otros niveles autonómicos, y otros mecanismos como el control social y la participación colectiva en instancias de decisión.

Pero los desafíos no terminan ahí, es preciso transformar dichos enunciados en prácticas políticas, es decir, realizar una reinvención del ejercicio democrático en sus distintas dimensiones para lograr la sostenibilidad del horizonte de transformaciones. Así, la reinvención de la democracia no pasa solo por el proceso de reformas sino, fundamentalmente por una reversión efectiva de las formas habituales de entender y ejercer la política. Esta reorientación demanda una recuperación de la sociedad civil como actor protagónico de las nuevas claves de la democracia, con capacidad de construir espacios públicos, demandas, propuestas, deliberaciones, escenarios de acuerdos en el marco de las luchas emancipatorias que se han generado desde hace más de una década.

La innovación estructural en el caso boliviano reside en que la presencia política de la diversidad a nivel nacional y local, está plasmada en la nueva Constitución, mediante la incorporación privilegiada del sujeto indígena originario campesino en el seno del Estado y la noción de plurinacionalidad.

Conscientes de que no basta una formulación constitucional, ponemos atención en las acciones políticas protagonizadas por sujetos provenientes del ámbito social a lo largo de esta última década, en una incursión exitosa que ha desplazado a los actores tradicionales del escenario electoral. Pero esta presencia renovada en el campo político no solo se ha expresado en el escenario electoral y representativo sino también en las movilizaciones callejeras. Las acciones colectivas discursivas y simbólicas de las organizaciones sociales afines o contrarias al gobierno, han acudido a repertorios de movilización como marchas, bloqueos, huelgas, vigilancias, cercos, y otros, así como la conformación de nuevos conglomerados como la Coordinadora Nacional para el Cambio (CONALCAM) afín al 
gobierno y el Consejo Nacional de Defensa de la Democracia (CONALDE) constituido en base a las organizaciones cívicas de oposición, entre otras.

No obstante, el espacio más interesante de análisis y novedad política es la participación de cierrtas organizaciones sociales en los aparatos del Estado, diluyendo una vez más - como sucedió el 52 - las fronteras entre el Estado y la sociedad.

Esta presencia de dirigentes de organizaciones sociales en el Estado tensiona otras variables críticas, por ejemplo, pone en cuestión la autonomía de las organizaciones sociales y sus capacidades de interlocución no subordinada al gobierno, la presencia de mediaciones prebendales y clientelares que contaminan estos vínculos, el desplazamiento de los fines ideológicos y programáticos por fines que responden al proyecto de poder del partido de gobierno, junto a la advertencia sobre la fetichización del poder.

Por último, no hay que perder de vista los factores estructurales de la crisis que son la base de una democratización sostenible, la búsqueda de la igualdad socio económica, el mejoramiento de las condiciones de vida de la población, así como el horizonte del bien común.

\section{NOTAS}

2. LACLAU Ernesto y MOUFFE Chantal, Hegemonía y alternativas políticas en América Latina., México, Ed. SXXI, 1980.

3. LACLAU Ernesto y MOUFFE Chantal, Hegemonía y alternativas políticas en América Latina., México, Ed. SXXI, 1980.

4. FOUCAULT Michel, El discurso del poder, México, Ed. Folios, 1993.

5. BOBBIO Norberto, El futuro de la democracia, México, Ed. FCE, 1993.

6. LINZ, VALENZUELA (Eds.), La crisis del presidencialismo, Madrid, Ed. Alianza, 1998.

7. O DONNEL Guillermo, "Hacia un Estado de y para la Democracia" in PNUD-Unión Europea Eds.: Democracia/Estado/Ciudadanía. Hacia un Estado de y para la Ciudadanía en América Latina, Lima, Ed. PNUD, 2008; NOVARO, Marcos, "Crisis de representación, neopopulismo y consolidación democrática" in Grompone (ed) Instituciones políticas y sociedad. Lecturas introductorias, Perú, Ed. IEP, 1995; PORTANTIERO, Juan Carlos. Los usos de Gramsci, México, Ed. Plaza y Valdés, 1987.

8. CALDERON F., LECHNER, N., Mas allá del Estado, más allá del mercado: la democracia, La Paz, Ed. Plural, 1998.

9. ARDITI Benjamín, “El giro a la izquierda en América Latina ¿Una política post-neoliberal?” in Democracia intercultural y representación política en América latina, La Paz, PNUD, 2010.

10. ARCHONDO Rafael, Los compadres al micrófono, La Paz, Hisbol, 1990.

11. De acuerdo con Zavaleta, el concepto de sociedad abigarrada se caracteriza por: la no unificación de la sociedad, es decir el escaso o distinto grado de compenetración entre sus elementos en torno al Estado, la falta de unidad nacional y consistencia interna de la clase dominante, la existencia de planos de determinación diacrónicos, o sea la convivencia de distintos contextos epocales en forma simultánea.

12. GARCIA LINERA Álvaro, "Sindicato, multitud y comunidad. Movimientos sociales y formas de autonomía política en Bolivia" in Tiempos de rebelión, La Paz, Ed. Muela del Diablo, 2001. 
13. Estas lecturas se encuentran en autores como Esteban Ticona, Xavier Albó, Silvia Rivera, y Luis Tapia entre los principales exponentes.

14. ZAVALETA René, Las masas en noviembre, La Paz, Ed. Juventud, 1983.

15. ZAVALETA René, "Bolivia la fuerza de la masa: de Banzer a Guevara Arze" in Escritos sociológicos y políticos., Cochabamba, CISO-UMSS, 1985.

16. LAVAU Georges, "Partidos y sistemas políticos: interacciones y funciones" en Calanchini (comp.), Partidos políticos y sistema político. Cuadernos de Ciencia Política No. 2., Montevideo, Fundación de Cultura Universitaria - Instituto de Ciencia Política, 1991.

17. ZEGADA Maria T, "Partidos en el poder: La ausencia de un sistema de representación política en Bolivia" in ZEGADA (Coord.), La representación política en Bolivia. Tendencias y desafíos, La Paz, IDEA - PNUD - FBDM, 2007.

18. Ibid.

19. Así, el Movimiento al Socialismo (MAS) desde mediados de la década de los noventa logró representaciones en concejos municipales y alcaldías y luego se trasladó al ámbito nacional y, junto al Movimiento Indígena Pachacuti (MIP), sumaron alrededor del $27 \%$ de los votos en los comicios nacionales del 2002 y, en las elecciones del 2005, el MAS con un discurso contestatario y de rechazo al sistema partidario rebasó, de manera inédita, la mayoría absoluta de votación (obtuvo el 53,4\%).

20. El MAS por ejemplo, es una organización política constituida por organizaciones sindicales con lógicas de tipo corporativo, y no es propiamente un partido político. El MIP es una derivación o un instrumento político del movimiento sindical indígena-campesino del altiplano. Dada la ubicación política actual del MAS en función gubernamental, sus desafíos son, además de romper con las lógicas del pasado y cumplir con la oferta de transformar el país, permanecer en el ámbito político y consolidarse como sujeto representativo, para lo cual requerirá un mínimo de institucionalidad organizativa.

21. RAVENTOS Ciska (comp.), Innovación democrática en el Sur. Participación y representación en Asia, Africa y América Latina, Buenos Aires, Ed. CLACSO, 2008.

22. MOUFFE Chantal, El retorno de lo político, España, Ed. Paidós, 1999.

23. LACLAU Ernesto, Conferencia de Ernesto Laclau en Lima, PUCP, 2009.

24. RANCIERE Jacques, El desacuerdo. Política y Filosofía, Buenos Aires, Ed. Nueva Visión, 1996.

25. STRASSER Carlos, Democracia \& Desigualdad. Sobre la "democracia real" a fines del siglo XX., Buenos Aires, Ed. CLACSO, 2000 y BORON Atilio, "Las ciencias sociales en la era neoliberal: entre la academia y el pensamiento crítico" in Tareas no. 122, Panamá, CELA, Centro de Estudios Latinoamericanos "Justo Arosemena": 2006.

26. MOUFFE Chantal, El retorno..., op. cit., p. 35.

27. BOURDIEU Pierre, El campo político, La Paz, Ed. Plural, 2001.

28. DUSSEL Enrique, 20 tesis de política, México, Ed. Siglo XXI, 2006.

29. FOUCAULT Michel, El discurso..., op. cit., p. 51.

30. SANTOS DE SOUZA Boaventura, Democracia de alta intensidad. Apuntes para democratizar la democracia, Cuaderno de Diálogo y Deliberación № 5, La Paz, Ed. CNE, 2004.

31. GRAMSCI Antonio, Notas sobre Maquiavelo, sobre política y sobre el Estado Moderno, México, Juan Pablo Editor, 1978.

32. Se trata de un concepto que, en palabras de Luis H. Antezana, adquiere un alto grado de profundidad, sedimentación, y permanencia; en que, diría Zavaleta, "las cosas comienzan a ser lo que son". En ese sentido, Zavaleta distingue al menos cuatro momentos constitutivos en la historia boliviana, el de la domesticación del hábitat en el Ande, el de la conquista señorial, el de la nación y el del Estado (Antezana s/f).

33. SANTOAS DA SOUZA, op. cit., p. 68. 
34. DANIGNO, OLVERA, PANVICHI, "Innovación democrática en América Latina: Una primera mirada al proyecto democrático-participativo" in Raventós (comp.), Innovación democrática en el Sur. Participación y representación en Asia, Africa y América Latina, Buenos Aires, Ed. CLACSO, 2008.

35. FOUCAULT Michel, op. cit., p. 89.

36. CHATTERJEE Partha, La nación en tiempo heterogéneo, Buenos Aires, Ed. Siglo XXI-CLACSO, 2007. 37. Propuesta para la nueva Constitución Política del Estado "Por un Estado plurinacional y la autodeterminación de los pueblos y naciones indígenas, originarias y campesinas" suscrita por la Asamblea Nacional de Organizaciones Indígenas, Originarias, Campesinas y de Colonizadores de Bolivia, compuesta por nueve organizaciones, entre ellas la CSUTCB, CIDOB, CONAMAQ, Sucre, CPES, 5 de agosto de 2006.

38. Nos referimos al Estado Plurinacional y al sujeto indígena originario campesino a la largo de la Constitución que proviene originalmente de la propuesta de las organizaciones sociales agrupadas en el Pacto de Unidad a la Asamblea Constituyente, y luego asumidas por la representación del MAS. El pacto aglutinaba alrededor de quince organizaciones sindicales, indígenas, originarias, y otras que construyeron una propuesta unificada con el objetivo estratégico de influir de manera más contundente en sus resultados.

39. RIVERA Silvia, "Democracia liberal y democracia de ayllu" in Miranda Pacheco (comp.), Bolivia en la hora de su modernización, México, Ed UNAM, 1993.

40. ZAVALETA René, "Bolivia: crisis de Estado: Una entrevista inédita, realizada por Roberto Laserna en el Perú, Lima, DESCO, 1980.

\section{RESÚMENES}

La democracia ha adquirido en Bolivia, estos últimos años, centralidad en el debate académico y político. Es que la democracia representativa junto a los otros elementos constitutivos del modelo anterior, como el neoliberalismo, la democracia pactada, el monopolio partidario, y otros, fueron cuestionados por la sociedad y las organizaciones, sino también mediante la construcción de una demanda colectiva de una profunda reforma estatal Se encuentra la noción de democracia vacía de contenido y adquiere sentido en la medida en que se articula a algún principio articulador o hegemónico particular ${ }^{2}$. En otras palabras, la discusión sobre la democracia o los adjetivos que se le atribuyan, se sitúan en el terreno de la disputa política estructural entre principios hegemónicos distintos que pugnan por el poder y por (re)articular los elementos ideológicos -en este caso la democracia-, que resultan fundamentales en determinada coyuntura, a sus respectivos discursos otorgándole sentido.

La démocratie est au centre du débat universitaire et politique en Bolivie, ces dernières années. Force est de constater que la démocratie représentative et d'autres éléments constitutifs du modèle politique précédent, tels que le néolibéralisme, la démocratie de pacte, le monopole des partis etc. ont été remis en question par la société et les organisations mais également grâce à la construction d'une demande collective d'une réforme profonde de l'État. La notion de démocratie a été vidée de son contenu et refait sens dans la mesure où elle s'articule avec un principe articulateur ou hégémonique précis. En d'autres termes, la discussion sur la démocratie ou les adjectifs qu'on lui attribue, se situe sur le terrain de la dispute politique structurelle entre des principes hégémoniques distincts qui se battent pour le pouvoir et pour (ré) articuler les 
éléments idéologiques - dans ce cas la démocratie -fondamentaux selon la conjoncture, pour leur propre discours.

ÍNDICE

Mots-clés: démocratie, représentation, discours, citoyenneté, hégémonie

Palabras claves: democracia, representación, discurso, ciudadanía, hegemonía

\section{AUTOR}

MARÍA TERESA ZEGADA

Universidad San Simón, Cochabamba, Bolivia 